\title{
Literatura afrofemenina en Cuba. Reyita, sencillamente. Testimonio de una negra cubana nonagenaria, de Daisy Rubiera Castillo ${ }^{1}$
}

\author{
Arianna Egües Cruz \\ Universidad de Cienfuegos "Carlos Rafael Rodríguez», Cienfuegos, Cuba. \\ https://orcid.org/0000-0001-8971-3098 \\ aegues@ucf.edu.cu \\ Osneidy León Bermúdez \\ Universidad Central "Marta Abreu» de Las Villas, Villa Clara, Cuba. \\ https://orcid.org/0000-0002-4099-8974 \\ osneidylb@uclv.edu.cu
}

\section{Resumen}

El presente trabajo se interesa por el libro Reyita, sencillamente. Testimonio de una negra cubana nonagenaria, escrito por la autora cubana Daisy Rubiera Castillo, en su calidad de testimonio literario que asume a la mujer afrodescendiente en su condición de sujeto social desplazado. Debido a la importancia otorgada al texto por la crítica y en aras de destacar su valor desde el punto de vista académico e intelectual, este acercamiento se propone analizar las temáticas que hacen de esta obra una muestra de la literatura afrofemenina en Cuba, a saber: la historia, la cultura, la memoria y las raíces, la discriminación y la identidad. Para ello, se auxilia de las herramientas teórico-metodológicas proporcionadas por los estudios de la literatura desde las perspectivas de género y de racialidad, y los criterios de aquellos especialistas que con anterioridad se han interesado por el testimonio Reyita, sencillamente... Además, este estudio se detiene en cuestiones formales de la obra, en especial, en su clasificación genérica como testimonio literario.

Palabras clave: Literatura afrofemenina cubana; mujer afrodescendiente; testimonio literario.

1 Procedencia del artículo: Este artículo es resultados de una investigación academica de interés personal. 


\section{Hfrofeminine literature in Cuba. Reyita, sencillamente. Testimonio de una negra cubana nonagenaria, by Daisy Rubiera Castillo}

\section{Hbstract}

This paper aims its attention at the book Reyita, sencillamente. Testimonio de una negra cubana nonagenaria, written by Cuban author Daisy Rubiera Castillo, a literary testimony that takes the Afrodescendant woman as a downtrodden social subject. Owing to the acceptance the text received from the critique and for highlighting its worth from the academic and intellectual standpoint, this approach advances an analysis of the questions the book deals with, which make it a sample of the Afrofeminine literature in Cuba, such as history, culture, memory and roots, discrimination and identity. To do so, the theoretical and methodological tools of the literary gender and race studies are used along with the criteria of specialists formerly interested in this piece. Besides that, this study also approaches the book's aesthetic side, namely its genre classification as a literary testimony.

Keywords: Afrofeminine Cuban literature; Afrodescendant woman; literary testimony.

Recibido: 06 de agosto del 2020. Aprobado: 02 de octubre del 2020

Artículo de reflexión

https://doi.org/10.25100/poligramas.v0i51.10901

\section{¿Cómo citar este artículo en MLH? - How to quote this article in MLA?}

Egües Cruz, Arianna. Y Osneidy León Bermúdez. "Literatura afrofemenina en Cuba. Reyita, sencillamente. Testimonio de una negra cubana nonagenaria, de Daisy Rubiera Castillo" Poligramas 51 (2020): n. pag. Web. Fecha de acceso (día, mes en mayúscula y abreviado, y año). 


\section{Umbral}

Para el ámbito de Latinoamérica y el Caribe, el germen del testimonio como género de la oficialidad se sitúa en el siglo XVI. El testimonio fue el resultado del esfuerzo de los españoles por justificar sus actos ante la Corona y ante el mundo, lo que se asocia con el acto de escribir y registrar lo que estaba ocurriendo a su alrededor: así la letra escrita se convierte en un correlato de la acción conquistadora (de Oviedo 74).

La crónica se halla entre sus expresiones iniciales. Ella tuvo como representantes a los hombres que protagonizaron la empresa del descubrimiento, la conquista y la exploración del territorio latinoamericano; sus narraciones toman la forma de cartas, relaciones o diarios que ofrecen recuentos de campañas o aventuras específicas. Las crónicas nacientes denotan una intención reflexiva sobre cuestiones relacionadas con el sometimiento de las culturas aborígenes, la evangelización y el proceso inicial de organización colonial (de Oviedo 81).

Entre las principales características en esta etapa, previa a la institucionalización del testimonio como género literario, estaba la representación de la cosmovisión eurocentrista de una supremacía blanca y patriarcal, y la narración de los sucesos sin ajustarse muchas veces a la realidad o distorsionándola por conveniencia. Esto condicionó las pautas del discurso oficial como el único capaz de narrar la historia.

Anterior al proceso de la conquista y colonización del continente latinoamericano, desde la visión europea, "el mundo de lo negro, era considerado primitivo, rústico, violento e inmoral; representaciones que basadas en la Génesis, libro onceno del Antiguo Testamento, fueron alimentadas por discursos catequizantes, diarios de exploradores y misioneros, así como por una abundante literatura, que pretendiéndose humanista, no hizo sino fomentar leyendas sobre el buen salvaje" (Romay Guerra, Cepos... 97). En efecto, "cuando la civilización europea entró en contacto con el mundo negro, con esos pueblos de salvajes, todo el mundo estuvo de acuerdo [con que]: esos negros eran el principio del mal" (Fanon 162).

A lo largo de los siglos XVI y XVIII, fueron introducidos millones de africanos, pertenecientes a doscientos grupos y subgrupos étnicos diferentes de África, los cuales constituyeron la fuerza de trabajo más importante para el desarrollo económico de la región (Rivera Pérez 67). De dichos grupos, a pesar de tener prohibido el acceso al lenguaje, la lectura y la escritura, como otro modo de dominación impuesto por el amo blanco, comenzaron a surgir otros testimonios, los de los subyugados que, privados de toda libertad física, extendieron a 
través del discurso testimonial su libertad de espíritu. Mediante la tradición oral estos testimonios mantuvieron el legado africano, a la vez que permitieron reconstruir la historia de los excluidos.

No obstante, otros criterios apuntan que el surgimiento del testimonio de los excluidos data del siglo XIX. Al respecto, se sostiene que estos "tienen su raíz en otra tradición narrativa del Caribe conocida como los relatos de esclavos... utilizados por los abolicionistas como propaganda para sus metas políticas, manipulando así las representaciones del sujeto negro" (Anderson 107). En consecuencia, los testimonios funcionan como un recurso para tamizar la realidad y mantener la trata, no para expresar la cosmovisión de ese grupo. Si bien es cierto que existe la intención de los escritores de situar al negro como sujeto literario en la narración, específicamente en la narrativa abolicionista, no se puede perder de vista que esta vertiente de la creación literaria se afanaba por perpetuar las ideologías discriminatorias de la época.

A la presentación del negro como personaje de la literatura abolicionista -o antiesclavista, como también se le conoce-, se suma la legitimación del negro como narrador, instancia en la que el género testimonio hace gala de su idoneidad para expresar la voz del negro en primera persona. Uno de los ejemplos más valorados y difundidos es el del poeta esclavo cubano Juan Francisco Manzano con su Autobiografía y sus poemas.

Sin embargo, son escasos los escritores de origen africano que gozaron de esa suerte. Una representación de esta afirmación son las escritoras afrodescendientes, a las cuales se les negó la oportunidad de (re)crear sus propios relatos y cuyo reconocimiento, en consecuencia, está en detrimento. Es por eso que se puede considerar que los antecedentes del testimonio, dentro de la literatura hecha por y sobre mujeres afrodescendientes de cualquier latitud, están en su memoria y en la tradición oral.

A partir del panorama histórico de la literatura afrofemenina en Cuba, se puede discernir que las principales cuestiones que imposibilitaron la creación literaria de la mujer negra fueron la esclavitud y sus consecuencias, especialmente la exclusión de este grupo de todas las esferas de la sociedad.

Durante la colonia, la trata - prohibida de manera oficial en 1817- se fomentó clandestinamente. Ello condicionó que un grupo enorme de mujeres que no conocían la lengua, ni las costumbres, y que estaban segmentadas en disímiles etnias, incrementaran la población negra (Martiatu Terry 2-3). Al igual que los hombres, las mujeres negras "traían consigo su 
propia identidad. Esta identidad borrada por el europeo, se estigmatizó bajo el emblema de una raza inferior. Pero en realidad, lo que trataron de hacer fue borrar la rica diversidad de los pueblos esclavizados y llevados" (Rojo 21).

No obstante, la mujer negra cumple un importante papel como transmisora del legado cultural africano. En la narración oral está la base de la escritura literaria posterior:

En un mundo diferente, el ambiente de las mujeres negras de la época colonial era el espacio doméstico, el campo, las minas y las plantaciones de azúcar y tabaco... [donde] se convirtieron en grandes observadoras e integraron a sus memorias las historias que les fueron contadas y los acontecimientos que presenciaron. Aún después de la abolición de la esclavitud, uno de los papeles que les cupo fue el de transmitir a sus hijos, nietos y a toda la comunidad afrodescendiente las historias de los suyos (da Trindades 78).

Su forma de resistencia no solo se basa en la conservación y transmisión de su cultura, sino también en la lucha contra la opresión del amo. Tal es el caso de la esclava de plantación, que "se destacó por su rebeldía, su participación muchas veces protagónica en los levantamientos, sublevaciones [y] en la organización de los palenques” (Martiatu Terry 3).

En Cuba, "la diáspora africana alcanzó sus mayores proporciones en los dos primeros tercios del siglo XIX" (Romay Guerra, Cepos... 52), mientras que el surgimiento de la filosofía natural en Europa y los estudios de los científicos naturalistas permiten el arribo del racismo científico, y con él una justificación de la desigualdad sociopolítica en la sociedad colonial, en términos biológico-raciales (Stolcke 94-95). Esto propicia que, en la Cuba colonial, se reproduzca y fortalezca la desigualdad de clase, que se manifiesta a través de la interacción de la discriminación racial y la jerarquía de género (Wade 122-123).

Con la abolición de la esclavitud y las nuevas realidades socioeconómicas del país, hubo una emigración de los afrodescendientes a las ciudades, sobre todo de mujeres. Si bien la gran mayoría de las mujeres negras de la época son independientes de la figura masculina, tienen una vida ardua, trabajos humildes y son las matriarcas del hogar, en oposición, hay un auge de los matrimonios interraciales, respaldados por un grupo de mujeres negras que lo asumen como aspiración para poder desempeñarse en oficios y profesiones, mejorando así en el orden económico. Ese deseo de "convertirse cultural y epistémicamente en blanco es constituido por este inconsciente colectivo que produce un complejo de inferioridad a través de mecanismos 
de individuación que genera afectos y subjetividades en los negros propios del imaginario racista blanco" (Fanon 280).

En cuanto al nivel de instrucción de la mujer negra, este era generalmente bajo. "En aquella época una parte muy exigua de la población sabía leer y escribir y que incluso en ciertos círculos de la clase media y alta se consideraba superfluo impartir instrucción a las mujeres más allá de lo necesario para administrar un hogar y para entretener el ocio" (Martiatu Terry 1). Surgen así numerosas revistas dedicadas a las féminas.

Los albores de la escritura de mujeres negras en Cuba pueden hallarse en la segunda mitad del siglo XIX, junto a las otras publicaciones femeninas que seguían las pautas de la literatura decimonónica. Se sigue el criterio de que:

En fecha temprana como 1888, dos años después de la abolición de la esclavitud... desde las páginas de la revista Minerva y otras, fueron capaces de articular un discurso completamente diferente al de las mujeres blancas. Abordaron en sus textos temas tales como la reivindicación de su identidad y de su africanía, la experiencia de la esclavitud, el orgullo racial y la exhortación a la superación cultural ... Ellas se expresaron con una clara concepción de género, raza y clase. Esto puede considerarse el antecedente del afrofeminismo (Martiatu Terry y Rubiera Castillo 3).

De manera comedida, serena, razonada, los artículos publicados en esta revista resultaron lo suficientemente enérgicos para esclarecer asuntos, concretar ideas, fijar puntos de vistas y definir actitudes (Rubiera Castillo, La mujer negra... párr. 2). Por tanto, no se puede absolutizar la no existencia de una literatura antes del siglo XX escrita por autoras negras en Cuba, aunque sí se puede afirmar que es una literatura poco numerosa, debido a su condición de sujeto social desplazado. Sin embargo, las muestras publicadas poseían un carácter emancipador, puesto que lograron apartar "la visión estereotipada que tenían en la sociedad y que se les concediera la posibilidad de mostrar otras historias, otras vertientes de ellas mismas, rompiendo con esas imágenes y prejuicios y creando nuevas condiciones de reconocimiento social y cultural" (da Trindades 9).

Con el advenimiento del siglo XX, se instaura en la realidad e historia cubanas la república neocolonial, la cual, a decir de Zuleica Romay, fue: 
La república burguesa neocolonial, período en el que a todas luces resultaba imposible soslayar la presencia de los descendientes de africanos en el mosaico de la cubanidad, la crítica social tendía a identificarlos como un lastre que dilataba la modernización, o como la inevitable carga que la parte blanca, culta y civilizada de la sociedad debía echarse a cuestas para sacar al país adelante (Romay Guerra, Elogio... 78).

A manera de paréntesis, es valioso subrayar que en esta etapa inicia la utilización del vocablo afrocubano. Este es socializado por Fernando Ortiz en su obra primigenia y se maneja para catalogar a los negros nacidos en Cuba en condición de criollos, convirtiéndose en una categoría social, económica y política que con el tiempo se despoja de la carga peyorativa. El prefijo afro va a servir tanto para describir a personas de piel negra como en la construcción de gentilicios identificativos de Afroamérica (Romay Guerra, Elogio... 175-178). Como resultado, se comienzan a llamar afrocubanos y afrocubanas a las personas con dicha ascendencia.

En otra instancia, un análisis conciso de la situación social de las féminas revela que:

Las mujeres afrocubanas padecieron los efectos de la descolonización característicos de las naciones que habían abolido el sistema esclavista: gran número de mano de obra desocupada, emigración desde el campo a la ciudad, inadaptación e incapacidad para integrarse en el mundo urbano, bajo índice de alfabetización, empleos precarios y mal remunerados que requerían escasa cualificación, incapacidad de articularse como colectivo, mediante asociación o partido político, e imposibilidad de promocionar en la escala social. Hasta el final de la república, las mujeres afrocubanas desempeñaron oficios que habían venido desarrollando durante el período colonial. En este contexto, el paradigma patriarcal de la mujer recluida en casa se perpetuó y vino a sancionar su rol como criadora y educadora de sus hijos (Ramírez Chicharro 821).

Desde el punto de vista de la escritura, se comienza a percibir, en las primeras décadas del siglo, un nuevo enfoque para tratar las problemáticas de dicho grupo social, que distaba de la visión eurofalocéntrica. En la década del 30, uno de los ejemplos es la figura de María Dámasa Jova, mulata villaclareña, que no solo se destacó en las letras, fundamentalmente en la poesía, sino también en la pedagogía, la edición, la promoción cultural y la política, con su trabajo «La 
situación de la mujer negra en Cuba», presentado en el Tercer Congreso Nacional Femenino (Riverón 63). En el documento manifiesta su pensamiento feminista negro.

Por otro lado, está la revista Adelante (1935-1939), que "entregó... artículos breves sobre problemas de contingencia nacional que afectaba a los afrocubanos, y en menor medida poemas y cuentos que [los] abordaran... [e] incorporó la temática sobre la condición de la mujer de la nación, siendo de gran relevancia por presentar artículos feministas escritos por mujeres negras" (Salinas 195); entre ellas, Cloris Tejo, Consuelo Serra, Ana Etchegoyen y Calixta Hernández.

Sobre los logros alcanzados por el discurso de la mujer negra en la república neocolonial, entre 1902 y 1959, se concluye:

Hasta 1958, el discurso de las mujeres negras en Cuba marcó el nivel alcanzado por su pensamiento. En la diversidad de los temas hay acumulada una interesante y valiosa información sobre los graves problemas que afectaban a la población negra en aquellos momentos. Discursos que, desde el punto de vista de la raza, la clase y el género, pudieron ser considerados peligrosos, por tanto debían pasar a la memoria, al olvido.

No fueron tomados en cuenta, con alguna salvedad, por quienes hicieron nuestros textos de historia y tampoco son del interés por quienes en los últimos años realizan estudios de género. Pero esos discursos resaltan la importancia de algunos de los momentos histórico-sociales de nuestra problemática racial y reflejan, lo persistente en ese siglo (Rubiera Castillo, La mujer negra... párr. 25-26).

En América Latina y el Caribe, desde la década de los 60 y los 70, comenzaron a gestarse una serie de movimientos como: los de liberación nacional, los de los negros e indígenas, la segunda ola del feminismo, entre otros. Estos estimularon importantes cambios en la política y en el pensamiento social crítico; además de plantear nuevas categorías (sexo, raza, sexualidad, etnia etc.) para entender lo social desde sus demandas identitarias y el reconocimiento (Curiel Pichardo, Género párr. 17).

En Cuba, fue "sólo después del triunfo de la Revolución que la mujer negra, [estuvo] favorecida por las campañas masivas de alfabetización" (da Trindades 62). Esto ocurre gracias al apoyo de proyectos populares impulsados por el comandante Fidel Castro. Es a partir de 
entonces que se puede realizar, en un primer momento, una revisión y una reescritura de la imagen que se formó de la mujer negra en etapas anteriores.

En este contexto histórico, nace el testimonio como género literario en el país y traspasa las fronteras nacionales. No obstante, los primeros ejemplares de testimonios literarios que salieron a la luz en Cuba no constituyeron textos escritos por féminas. Las décadas iniciales de la Revolución se caracterizaron por tener poca escritura de testimonios creados por mujeres y "los temas tuvieron que acomodarse a la ideología del régimen que anhelaba fortalecer la nación basada en la inclusión de clase, dentro del dogma de la identidad única revolucionaria" (da Trindades 63). Los ejemplos que se pueden citar son Manuela la mexicana (1968), editado por Aída García Alonso, y Lengua de pájaro (1971), de Nancy Morejón y Carmen Gonce. Mientras, la política cultural del país promovió que en la creación literaria se favoreciera el género testimonio, a través de su inclusión en el certamen literario de Casa de las Américas en su edición de 1970 y su difusión en la colección Premio de su editorial.

En otra dirección, es importante destacar que:

A pesar de la apertura, en la década de los años 90, de la literatura cubana hegemónica a una literatura escrita por mujeres, la mayoría de esos textos no se redactaban desde una perspectiva feminista, ni tampoco a partir de una identidad afrodescendiente... No obstante muchos esfuerzos se hicieron desde el mundo académico e intelectual para confrontar el anti-feminismo arraigado desde las décadas anteriores en la sociedad cubana, y finalmente lograr que se formara una consciencia feminista propia de Cuba (Anderson 108).

Es necesario aclarar que "dentro de la producción literaria afrofemenina... la narrativa en prosa, sea la novela histórica o la narrativa del género testimonial o autobigráfico, todavía se encuentra en un estado incipiente" (da Trindades 19). Los exponentes de la narrativa afrofemenina que se pueden mencionar son la novela Cartas al cielo (1997) de Teresa Cárdenas, así como Santa lujuria o papeles de blanco (1998), El Harén de Oviedo (2002) e Inglesa por un año (2006) de Marta Rojas, y, dentro de la cuentística, Kele kele (1987) de Excilia Saldaña y Sobre las olas y otros cuentos (2009) de Inés María Martiatu.

Sin embargo, no fue hasta el logro del galardón de Primera Mención, en la categoría de testimonio, en la edición de 1996 del certamen literario de Casa de las Américas, obtenida por 
la obra Reyita, sencillamente. Testimonio de una negra cubana nonagenaria (1997) de Daisy Rubiera Castillo, que la visión sobre el testimonio escrito por mujeres afrodescendientes en Cuba cambió.

Junto a Rubiera, otras dos escritoras, Georgina Herrera y Nancy Morejón -dedicadas con mayor asiduidad al cultivo de la poesía-, conforman una tríada de representantes del testimonio dentro del contexto cubano. En consecuencia, ellas:

...juegan con la intersubjetividad de la mujer negra representándola como sujetos activos... las alejan de la representación de víctima y seres subordinados y pasivos. Son narrativas que dejan florecer historias cuestionan sus vidas y las hacen triunfadoras de los obstáculos históricos y sociales. Ellas revelan una nueva identidad que conecta el activismo político intercalado con otros roles (da Trindades 127).

En los inicios del siglo XXI, se destacan dos ejemplos importantes de narrativa testimonial que imbrican a dos de las autoras antes mencionadas, Daisy Rubiera y Georgina Herrera, lo que nos inclina a vislumbrar un evidente interés en el cultivo de este género literario. El primero, Golpeando la memoria: testimonio de una poeta cubana afrodescendiente (2005), nace del proyecto «Memorias e Historias Orales de la Revolución Cubana» (2005-2007) para abordar la vida de la escritora y activista Georgina Herrera, que fue coordinado y editado por ella junto a Daisy Rubiera. Por otro lado, está Desafío al silencio (2010) de la propia Rubiera, que tiene como protagonistas a trece mujeres cubanas y donde se afronta la temática de la violencia de género tanto física como psicológica.

Autora de tres testimonios en este panorama no tan vasto, sale a relucir la creación de Daisy Rubiera Castillo. Ella se destaca por su labor a favor de la mujer negra desde el activismo social y la creación artística. Así surgen de su mano artículos y ensayos, entre los que se ubican: "La mujer negra en Cuba: Mediados del siglo XVI- mediados del XIX» (1996), "Perfil de la mujer negra en Cuba» (2003), "El discurso de la mujer negra: ayer, hoy" (2011), "Mujer negra y violencia: Diferentes formas de discriminación» (2011) y "La masacre de 1912: memoria del olvido» (2012).

A lo anterior, se suma su participación activa en la creación de proyectos y sobre todo su labor como compiladora y editora en la publicación de libros. Entre estos se pueden señalar los tres testimonios referidos, además de los libros: Aires de la memoria (2011), Afrocubanas: 
Historia, pensamiento y prácticas culturales. Selección de textos (2011) y Resurgiendo del silencio: mujeres negras en la historia de Cuba. Selección de textos (2016).

Tal quehacer no ha pasado desapercibido por las estudiosas de la escritura de mujeres en Cuba y del testimonio de afrodescendientes; ejemplo de ellas son: Zaida Capote Cruz (2008), Aymée Rivera Pérez (2012), Maya Anderson (2013) y Luciana da Trindades Prestes (2015).

La siguiente idea resume la intención de la escritura testimonial de Rubiera. Ella "logra incorporar las voces de las mujeres afrodescendientes al canon literario cubano contemporáneo, reivindicando una identidad afrodescendiente y feminista..., otorga a la mujer afrocubana un lugar importante dentro de la literatura cubana, y contribuye a la formación de una consciencia feminista afrodescendiente en Cuba" (Anderson 106).

Es así que Reyita, sencillamente. Testimonio de una negra cubana nonagenaria se ubica en unos, aproximadamente, noventa años de la historia de la nación cubana, ocurrida en el pasado y contada a través de la historia de vida de María de los Reyes Bueno, una afrocubana. Está escrita en una prosa llana, con un lenguaje sencillo nutrido de coloquialismos. En ella predomina un narrador personaje en primera persona, Reyita, quien en algunos instantes deja entrever que su narratario es su hija, Daisy Rubiera, lo que constituye un remanente en el texto editado del proceso previo de recolección de la historia mediante entrevistas. En cuanto a su estructura, está compuesta por cuatro capítulos y 56 epígrafes, todos con títulos tomados de la obra de la poetisa cubana Georgina Herrera, en franca pleitesía hacia la poetisa cubana, también interesada en la denuncia de la discriminación de la mujer negra. La mayor parte de la obra está dedicada a su personaje protagónico; sin embargo, aparecen algunos epígrafes en los que Reyita narra, a manera de relatos intercalados, la historia de otros personajes negros que poseen un determinado rasgo de parentesco con ella.

A partir de la bibliografía consultada, se puede subrayar que "Reyita, merece ser destacada por ser la primera narrativa testimonial en prosa cubana que trata de la problemática de género interpuesta con la cuestión racial" (da Trindades 65). Se trabaja con este criterio aun cuando resulta absoluto, porque destaca el propósito esencial de la obra, el cual le es reconocido por otros autores revisados, aunque se demuestre que no es la primera obra en tratar esta problemática en Cuba. Dicho criterio se justifica si se tiene en cuenta que "la narrativa basada en la oralidad se estableció como un componente importante del discurso de la identidad 
cubana,... [eran] obras narrativas que [retrataban] la resistencia y la autorrepresentación desde la óptica masculina. En cambio, Reyita es la primera narrativa que clama por una voz femenina" (da Trindades 65). También se alude a "la poca frecuencia con la que textos similares a Reyita, sencillamente afloran en el panorama nacional" (Capote Cruz 78).

Sin embargo, el texto, a pesar de ser representativo de su tipo en Cuba, no ha recibido el suficiente reconocimiento en el país, pues, según la crítica, en nuestros predios "los debates en torno al libro tienden a ignorar las cuestiones de raza" (Rivera Pérez 249). A la par, los estudios literarios feministas sobre la escritura de las mujeres afrodescendientes, en la actualidad, siguen prestando mayor atención a los géneros de ficción, sobre todo a la poesía.

Es por eso que se entiende esta obra como muestra poco estudiada de la literatura afrofemenina hecha en Cuba. Para su estudio, singular importancia reviste su clasificación genérica, ya que los géneros menores o ancilares han sido poco estudiados y la crítica ha señalado una recurrente predilección entre género, raza y testimonio -o géneros no ficcionales en general-; por tanto, se sostiene la idea de que el género escogido por la autora viabiliza el contenido y el tono de denuncia de la obra.

\section{Cuestiones de método}

No se debe pasar por alto que las investigaciones, que encuentran en el testimonio la realización de un género literario, no están exentas de polémicas, tanto por su definición como por sus rasgos, características y clasificación.

En este mare magnum de diferentes posturas se pueden generalizar los criterios de teóricos como: Carlo Ginzburg, Jorge Eduardo Suárez Gómez, John Beverley y Mark Zimmerman, George Yúdice, Elzbieta Sklodowska y Natalia Tobón, para expresar que en dicho género existe un testimoniante que, haciendo las veces de narrador y protagonista de la historia, es el que relata los eventos de forma oral a través de su propia experiencia, en su condición de representante de una memoria e identidad colectiva; el testimonialista, por su lado, con su función de editor o escritor, es el encargado de escribir y producir el testimonio a través de la transcripción y edición de dicho relato, sin perder de vista la verosimilitud y con la intención de denunciar situaciones de opresión y de ofrecer una visión alternativa a la historia oficial y hegemónica. Estos elementos, unidos a los de autoras que se han dedicado a examinar las particularidades de la obra, como Karen Ruth Kornweibel, Mirta Rodríguez Calderón, entre otras, 
sirven como herramientas de apoyo para su caracterización desde el punto de vista genérico y formal.

Con ese objetivo, se siguen los derroteros de la perspectiva cualitativa, "modalidad epistemológica particularmente útil para la investigación de las artes" (Álvarez Álvarez y Barreto Argilagos 108). Esta posibilita que los fenómenos sociales sean abordados a partir de metalenguajes propios de las ciencias humanísticas, en este caso, la literatura. Fundamentalmente, se emplea el método de análisis de textos, y, en especial, el análisis de contenido, a través del criterio de cantidad y calidad, dentro del campo intratextual. Además, se auxilia de las premisas de los estudios de género y racialidad. Para una mejor compresión, es vital indagar sobre estos últimos dos métodos.

Los estudios de género surgen a partir de la herramienta conceptual o categoría analítica conocida como género, que tiene como antecedentes los estudios de Margaret Mead, Simone de Beauvoir y Kate Millett, y que es elaborada por teóricas como Ann Oakley, Gayle Rubin, entre otras (Curiel Pichardo, Género párr. 26-30). Dicha categoría constituyó el eje central de las investigaciones sobre la mujer, luego de la conformación de los estudios teóricos literarios feministas, que se derivaron del feminismo, como corriente de pensamiento.

El vínculo de los estudios de género con la racialidad tiene su germen en la tercera etapa del feminismo, conocida como posfeminismo, que abogaba por el reconocimiento de la pluralidad y la teorización del contraste dentro de la diferenciación sexual. "La importancia del género para la comprensión de las identidades racial y étnica provino de la insatisfacción de las feministas negras con las actitudes patriarcales de los hombres negros activistas, por un lado; y por otro, con el etnocentrismo de las feministas blancas" (Wade 123).

A través del "feminismo negro estadounidense, que ponía en diálogo el marxismo, el feminismo y el movimiento negro, se hicieron numerosas contribuciones que buscaron conceptualizar la articulación de las relaciones de clase, de género y de raza" (Viveros Vigoya, La sexualización... 173). Esta nueva percepción de "la intersección entre género, raza y clase suscitó cuestiones nuevas y complejas acerca de la relación entre ideologías biológico-raciales que legitiman estructuras de desigualdad económico-políticas y la organización de la reproducción social, y entre el control del sexo, de los cuerpos sexuados, de la sexualidad y las relaciones de género... [y] las circunstancias históricas" (Stolcke 93). 
Impulsadas por este contexto, las críticas de raza negra exigen una estética feminista que aborde políticas raciales y sexuales, en los estudios sobre las escritoras negras y del Tercer Mundo. Las representantes de esta etapa, en la década del 80, logran que se perciba al sujeto femenino más allá del género sexual, y que elementos como: la raza, la clase, la etnia, la sexualidad y la región, sean también constituyentes de él. Así, desde la crítica literaria feminista, la doble marginación de la mujer negra también es estudiada. Entre las teóricas que examinan la cuestión de género y raza en la literatura y sociedad se encuentran: Mary Helen Washington, Bárbara Smith, Angela Davies, Carole Boyce Davis, bell hooks, Valerie Smith, Deborah McDowell, entre otras.

Desde la década del 70, existían dos tipos de modalidades de crítica feminista en la literatura: la lectura feminista o crítica feminista y la ginocrítica. Esta última se dedica al "estudio de las mujeres como escritoras, y sus objetos de estudio son la historia, los estilos, los temas, los géneros y las estructuras de las escrituras de mujeres; la psicodinámica de la creatividad femenina; la trayectoria individual o colectiva en las carreras de las mujeres; y la evolución, así como las leyes, de la tradición literaria femenina" (Showalter 605).

La ginocrítica se divide en cuatro modelos diferentes. El último modelo, conocido como teoría de la cultura, "reconoce que existen diferencias importantes entre las mujeres como escritoras: clase social, raza, nacionalidad e historia, constituyen determinantes literarios tan significativos como el género" (Showalter 626).

Al relacionar esta teoría de la cultura con la obra de las autoras negras, señala Bárbara Smith, "(...) Las escritoras negras constituyen una tradición literaria identificable (...) temáticas, estilística, estética y conceptualmente. Las escritoras negras manifiestan aproximaciones comunes hacia el acto de creación literaria como resultado directo de la experiencia política, social, y económica y especifica que se han visto obligadas a compartir" (Showalter 633).

Es con base en las temáticas de una obra literaria de una autora afrodescendiente que se enfoca este estudio. Como herramientas de apoyo para delimitar cuáles se deben incluir, se siguen los criterios de investigadoras como Luciana da Trindades Prestes, Maya Anderson, Aymée Rivera Pérez y Zaida Capote Cruz. Dichos criterios se refieren a que Daisy Rubiera Castillo exhibe en Reyita, sencillamente... una serie de cuestiones que apuntan a la situación de la mujer negra, como son: "la importancia del sujeto afrofemenino como ser activo en la 
identidad del país" (da Trindades 128); "la vida y obra de mujeres afrocubanas enfocándose específicamente en la violencia de género, el mundo de la cultura y las religiones afrocubanas" (Anderson 106); "la discriminación racial y de género" (Rivera Pérez 248); "la pobreza lo mismo que el racismo" (Capote Cruz 80), y "la demanda un espacio dentro del discurso sobre la historia de Cuba, y en especial, en lo referente a la vida de los negros" (Capote Cruz 83).

Bajo esta égida, el presente trabajo pretende analizar la contribución del testimonio de una negra cubana nonagenaria, Reyita, sencillamente..., a la literatura afrofemenina en Cuba, en cuanto al tratamiento privilegiado y esencial dentro de la obra de temáticas afrofemeninas.

\section{En voz de Reyita}

La obra Reyita, sencillamente. Testimonio de una negra cubana nonagenaria es reconocida desde su título como un testimonio y concebida a cabalidad como tal en el desarrollo del libro. De acuerdo con los textos teóricos revisados a la sazón, la misma puede ser clasificada como un testimonio literario.

En un inicio, este libro, como "proyecto testimonial" (Tobón 64), es el resultado de los tres niveles: el de la narración de Reyita, el de la edición de Daisy Rubiera y el de la lectura de esta investigación, sin que sea posible discernir cada nivel como una parte sino tomándolo como un todo.

Por otro lado, la obra parte de la realidad de una testimoniante, Reyita, que se recrea con la escritura fiel de Daisy Rubiera, hasta crear, en cumplimiento de lo sostenido por la bibliografía consultada, una cadena de mediación entre lo que pasó, lo que contó el narrador y lo que escribe el editor.

El cumplimiento cabal del testimonio se evidencia cuando en este sentido Rubiera reconoce su elaboración como autora del texto escrito, que tuvo una génesis en la oralidad, y, además, declara su intencionalidad con la realización de este proyecto. A partir de una entrevista facilitada a las autoras de este trabajo, expresa: "En la elaboración de este libro las mayores dificultades estuvieron en el traslado de la narrativa oral a la escritura. En organizar en temas la esencia de la vida narrada para darle significado histórico y literario a esa memoria sin que perdiera los códigos..." (Egües Cruz 143). 
Como tal, está creado por un testimonialista, la investigadora y autora, Daisy Rubiera, quien estuvo a cargo de la edición y elaboración, y la organización del testimonio ofrecido por Reyita, sujeto femenino protagonista del relato, a través de entrevistas.

Aun cuando se destaca asiduamente que la relación entre testimoniante y editor de esta obra es la de hija y madre, no se encuentra en ello una situación especial que desvirtúe o cambie lo antes dicho y que es común a otros testimonios. A la vez, resulta imposible tanto negar como demostrar el intimismo y la confianza que debió existir en las sesiones de trabajo, así como la intromisión de lo sabido por Rubiera en su condición de hija ante lo que no fue declarado por su madre y que forma parte de la historia. Al respecto, esta investigación solo puede mantenerse al margen, toda vez que, aun cuando se ha tenido acceso a la autora mediante una entrevista, este deslinde no resulta oportuno para los propósitos de este estudio.

La relación testimoniante-editor vuelve a ser señalada por la crítica; se trata de dos mujeres afrodescendientes que han atravesado por experiencias similares, lo que vuelve a hacer muy porosos los límites entre la voz emisora de Daisy y la de Reyita.

Lo anterior es, ante todo, una propuesta interpretativa con la cual se puede o no concordar, sin negar que el activismo en favor de la emancipación de la mujer negra de Rubiera inunda todas las palabras de la obra. Se considera que ese mismo interés es el que la hace sacar a la luz el testimonio de su madre, que de antemano ella conoce, pues es una historia que vive y es a la par la historia de la mujer negra cubana. Aun cuando no es posible una demostración, no se considera que Reyita sea un personaje de papel al que la autora puso ideas y criterios suyos.

Reyita, sencillamente..., como parte del testimonio literario, posee la característica de hibridez, donde los límites entre el mundo de ficción y la realidad desaparecen. Los elementos que la componen son: los recursos del lenguaje literario, la voz y la ruptura de la ficcionalidad literaria.

La obra es un testimonio y, como tal, es la transcripción de la grabación del archivo original y fuente, documentos a los cuales no se tuvo acceso. Por lo que cuanto se ve en el libro es parte de la interpretación y análisis. El libro se toma como una elaboración artística de la grabación original de una serie de entrevistas realizadas a Reyita, que fue elaborado, seleccionado y organizado por Daisy, su autora. 
Bajo ese sentido, se pueden encontrar en la obra como parte de la creación literaria algunos recursos artísticos. Entre los relacionados con el lenguaje está el uso de refranes como «más sabe el diablo por viejo que por diablo» y las locuciones propias del lenguaje coloquial, que Daisy ha mantenido para darle viveza y colorido a la caracterización de personajes, entre las que se pueden citar: «me empeñara hasta los ojos», «él no veía más allá de su nariz», «todo le salió a pedir de boca», los apodos con connotaciones peyorativas como «mona», «jocicúa» y «bruja», y diminutivos paternalistas que enarbolan la inferioridad como «negrita».

Por otro lado, se emplean recursos narrativos como la descripción, específicamente, la de los personajes y el retrato, identificado por algunos críticos como aquel en el que se acude a la descripción física y moral de un personaje. Igualmente, aparecen los diálogos, los cuales se considera que son más elaboración de la autora que reproducción de la realidad, debido a que están acotados concretamente, lo que no evidencia el lenguaje común de una conversación, sino un remedo literario del lenguaje oral.

Otro recurso de creación literaria, esta vez, en relación con la estructuración de la obra, son los relatos intercalados -ya sean elaboración de Daisy o con respecto a la forma en que Reyita contó la historia-, que hacen de la obra un acto de elaboración artística.

En cuanto a la hibridez del texto, otro de los elementos que la evidencia, según los criterios de varias autoras en la bibliografía consultada, es la voz, la cual se erige como una problemática. Para unas, la voz de la autora se deja escuchar a través del personaje protagónico, lo que sugiere que Daisy Rubiera, según Karen Ruth Kornweibel: "no es un conducto neutral por el cual pasa intacta la voz de su madre" (73). Mientras que para otras como Mirta Rodríguez Calderón: "se defiende la prevalencia de la voz de Reyita en el texto" (Rivera Pérez 248). Sin embargo, para Maya Anderson:

Esta obra, como todos los testimonios, tiene una voz narrativa plural que se caracteriza por su alto grado de afecto y complicidad. Esta confianza se ve reflejada en el paratexto, donde se explicita la colaboración estrecha entre varias mujeres: Mirta Rodríguez Calderón escribe el prólogo, Sonnia Moro ayuda a Daisy Rubiera en la investigación y los poemas de Georgina Herrera encabezan los capítulos (110).

Por su parte, Aymée Rivera se interesa por las mediaciones de las voces de la testimoniante y la escritora, negando la posibilidad de que la voz de la autora permanezca al 
margen. Aunque esta intelectual se debate entre dos posturas. En la primera, Rivera opina que: "la forma y el enfoque del texto indican que Rubiera, es una activa agente en la construcción de la historia de su madre" (248). En la segunda, aborda cómo el personaje protagónico no debe ser visto como una individualidad. Rivera admite que: "tal como se presenta en este testimonio, es, a la vez, típica y excepcional. Ella es la típica mujer afro-cubana y es también el símbolo de la nación" (248). Finalmente, concuerda con que la voz de Reyita no es ya la de María de los Reyes ni la de su hija Daisy, sino la de un grupo.

Este último criterio es el que se asume en el siguiente trabajo: la voz de Reyita como la de un grupo social y la voz de la autora que entra en juego en tanto miembro y defensora de ese grupo social, más que por su condición de hija. Sin embargo, este rasgo, que puede ser compartido con otros géneros, no debe borrar la peculiaridad de esta obra testimonial, es decir, que nace del material que ofrece el testimonio brindado por Reyita.

En otra cuerda, por su lado, aparece la problemática de la ruptura de la ficcionalidad literaria en la narración. La obra está narrada en primera persona, desde el punto de vista de Reyita, aunque escrita por su hija Daisy Rubiera Castillo. Singular resulta el último acápite del libro, titulado «iNuevas Verdades!», en el que el sujeto emisor ya no es la protagonista, sino la autora. Una serie de notas, un testimonio gráfico, así como una bibliografía, son documentos que ayudan a comprender que la obra propone a Reyita como sujeto y narradora de la historia principal, y que Daisy Rubiera, en su condición de investigadora, solo aparece, y así se declara cuando: "describe un viaje que hizo a Cárdenas para verificar algunos de los hechos de la historia de su madre y comprender la actitud de su padre, ya que, como ella le dice al lector, su madre no quería caracterizarlo a él" (Rivera Pérez 249).

La sección también funciona como parte argumento de veracidad... El texto incluye una sección de notas que explican el significado de los nombres, fechas y acontecimientos mencionados en la historia. La bibliografía al final contiene una sección de "Fuentes documentales" y una lista de todas las personas que Rubiera entrevistó al escribir el libro. La lista incluye a tres historiadores, un sociólogo y un superviviente de la llamada Guerrita de los negros de 1912 (Rivera Pérez 250).

Como se ha podido vislumbrar en el análisis anterior, se está en presencia de un testimonio literario que, como tal, posee un narrador-personaje-protagonista, María de los Reyes 
o Reyita, encargado de entregar al lector una historia pretendida real, en la cual cuenta su vida, bajo el uso de la primera persona, a un narratario explícito, extradiegético retórico, su hija Daisy Rubiera. El asunto de la obra es la historia de la mujer afrocubana, aquella no abordada en los registros oficiales y que ha estado silenciada, aquella que devela el punto de vista de este grupo social, a través de las experiencias de la colectividad dentro de la sociedad cubana, como también de la individualidad de la protagonista y la de todas las mujeres negras de su familia. Dichos personajes femeninos negros, que existieron fuera de la ficción literaria, son: Isabel (madre); Antonina, más conocida como "Tatica» (abuela materna); Emiliana, cariñosamente tildada de «Mamacita» (abuela paterna); Casilda y Nestora (tías maternas), y Margarita Planas, a quien se le llamaba, "Doña Mangá» (tía política). Estos personajes son referidos por la protagonista por medio de una doble focalización, tanto interna como externa.

La trama, aunque no posee un orden cronológico estricto, sí evidencia un avance progresivo de los acontecimientos desde la niñez hasta la vejez de la protagonista. Ella, a través de su narración, en un lapso de noventa años aproximadamente, evoca la importancia del sujeto afrofemenino como ser actuante en la sociedad cubana. Por ende, la temática central es la problemática de género y raza que ha sufrido dicho grupo. De esta, se derivan las que se analizan a continuación, las cuales demuestran que la obra es un exponente de la literatura afrofemenina cubana.

\section{La mujer afrocubana y su historia}

Reyita expresa:

...últimamente me he dedicado a leer todo lo que se ha escrito y se escribe sobre los negros-aunque no es mucho-, pero algunas de las cosas que se dicen me disgustan; no sé, creo que no se va al fondo, no se entrevista a los viejos que fuimos los que en definitiva sufrimos toda aquella situación. Creo que en la medida en que nos vayamos muriendo, más se alejaran los escritores de la verdad (Rubiera Castillo, Reyita... 25).

Para rellenar esos vacíos de la historia y acercar al lector a la verdad, la protagonista primero se traslada a sus orígenes y se remonta a la Colonia, con el fin de narrar cómo fue la vida de sus antepasadas negras (Antonina, Casilda, Nestora e Isabel), personajes a través de 
los cuales describe el proceso de introducción de negros esclavos en Cuba desde el aprisionamiento en África, el traslado, la transportación y el arribo hasta la venta.

Después, relata el sometimiento dentro de nuestro territorio como un instrumento de trabajo en las tareas del campo, haciendo referencia constante a la explotación, la sumisión, el servilismo o degradación y la desigualdad. Al mismo tiempo, caracteriza la abolición de la esclavitud a través de la historia de su madre Isabel, privada de libertad dentro del hogar del amo, su propio padre, que la utiliza como doméstica o criada bajo el sufrimiento propio por medio del maltrato y la violencia.

De la misma forma, rememora cómo ocurre el enfrentamiento durante la época colonial tanto de los hombres como de las mujeres negras por su mejoramiento social, mediante los hechos en los que participaron directamente. Primero, con la incorporación como mambisas de su abuela materna y su mamá a las guerras de 1868 y de 1895, y el papel desempeñado en la manigua, y segundo, con las consecuencias que estos eventos les acarrean, donde todas pierden a muchos de sus hijos, ya sea durante la gesta independentista o por el ambiente hostil en el que vivían, respectivamente.

Más adelante, entabla su relación con el Partido Independiente de Color de 1912 y hace mención de su objetivo, sus demandas y sus principales figuras, Pedro Ivonet y Evaristo Estenoz, a los cuales conoce. Luego, desentraña la verdad sobre la llamada "guerrita de los negros», alzamiento que ocurre como protesta ante la «Enmienda Morúa», la cual promulgaba la incapacidad de afiliación a un partido político por personas de una misma raza y que es utilizada por Mario García Menocal para sus fines de elección presidencial. Como consecuencia, ocurre la masacre de muchos negros, entre ellos, el tío de Reyita, Juan, así como el aprisionamiento injusto de otros, como «Doña Mangá», tía política de Reyita, presa, durante seis meses, por ser presidenta del Comité de Damas Pro Partido Independiente de Color. La protagonista comenta: "El resultado fue que Cuba quedó más dividida que nunca antes. Los blancos de una parte y los negros de otra. Los negros sentían odio y rencor por los blancos, y estos humillaban y vejaban a los negros. Y así fue durante mucho tiempo" (Rubiera Castillo, Reyita... 48).

Con el avance de la obra, el personaje protagónico centra la historia de la mujer negra en la república neocolonial, a partir de su propia experiencia. En los primeros años, dentro del apartado titulado "Negros con negros», puntualiza su incorporación y participación en actividades a favor del movimiento Macus Garavey, en 1921, para emigrar a África. 
Durante la década del 40, en el apartado «Se hizo mi voluntad», habla sobre su posición ante la tiranía a través de sus concepciones ideológicas, que la llevan a integrar el Partido Socialista Popular y a la par, sobre las acciones que desempeña, directa o indirectamente a favor de la causa revolucionaria como: su participación en reuniones y actividades para recaudar fondos o el apoyo a sus hijos durante la lucha rebelde en las montañas.

Más tarde, con el triunfo de la Revolución cubana, hace referencia a su integración, en sus primeros años, a los programas sociales como profesora durante la Campaña de Alfabetización, participante en la recogida de caña, en la campaña de la trilla de café, en los trabajos voluntarios, y a las organizaciones políticas y de masas como: el Comité de Defensa, la Federación de Mujeres Cubanas y la Milicia Nacional Revolucionaria. Todo lo anterior hace de Reyita, según su testimonio, una revolucionaria totalmente comprometida.

\section{La mujer afrocubana y su cultura}

En la narración de Reyita se percibe el uso de la memoria cultural, tanto por ella como por los otros personajes femeninos negros. En el personaje protagónico esta característica demuestra la imbricación de la cultura cubana, mientras que en sus antepasadas se evidencia la permanencia de la cultura africana.

Reyita, en primer lugar, se autocaracteriza como una especialista de la comida tradicional cubana que se aprecia en el acápite «El amor entra por la cocina», donde no solo se enuncian platos de dulces y sopas, como el pudín de malanga, el ajiaco santiaguero y la sopa de ajos, sino que se especifican las recetas de los mismos. También, hace referencia a la comida ritual que dispone a sus santos como ofrendas de agradecimiento.

Por otro lado, se refiere a cómo las labores del hogar como el tejido, que lo aprende en su juventud y luego en su vejez, le permite ganar dinero y satisfacer de cierta forma las necesidades de sus nietos, y cómo transmite sus cantos de cuna, heredados de sus antepasadas y tradicionales, a sus descendientes: "Macuní suncí», "macuní sunzá» y "Don Tribilín».

Un elemento esencial en su narración lo constituye la práctica de sus creencias religiosas. Estas se aprecian en epígrafes muy puntuales como son: "Los Misterios», "iMisericordia, misericordia!», "iPréstemelo, Virgencita!», "La promesa a San Lázaro», "Mis visiones», "Mis creencias religiosas», "Y tenía una gracia», y en otros epígrafes de forma aislada. La primera de 
estas prácticas es el espiritismo, que en ella se manifiesta como espiritismo cruzao. Este se evidencia en el personaje protagónico a través de sus visiones o con el cuidado a espíritus, a quienes les realiza rezo de oraciones, pone velas, flores o un vaso de agua, o echa un cubo de agua a las 12:00 del día en la entrada de la casa, entre otros.

La segunda es el catolicismo. Dicha creencia religiosa está ligada, por un lado, a la religión afrocubana, en especial, a la yoruba, debido a que se percibe el sincretismo de los orishas con los santos católicos: Babalú Ayé-San Lázaro y Oshún-Virgen de la Caridad, y quienes componen su apoyo espiritual en las situaciones más adversas que le ocurren en la vida. Mientras que, por otro lado, las características del espiritismo permiten a la protagonista, por medio de plegarias, rezos, despojos e irradiaciones, vincular, en un velorio de San Lázaro, a este con el Ángel de la Guarda y el Espíritu Protector. Así, Reyita devela su cosmovisión del mundo y se convierte en la portavoz del rescate de todos aquellos elementos que integran el acervo cultural religioso cubano.

Finalmente, su vocabulario es muestra de conservación del legado afrocubano. En el personaje protagónico es recurrente el uso de términos de este componente cultural, por ejemplo: "chambras», "cunyayos», "mela'o», "cocá», "pasa», "bemba», "cañadón», "bellaca», "Sanaquerías», «jolongo», «narigoneros», "quimbuleros», «manicheo», entre otros. De igual forma, se observa el empleo del refranero popular como: "más sabe el diablo por viejo que por diablo», «en la casa del pobre la felicidad dura poco» y las locuciones propias del lenguaje coloquial, entre las que se pueden citar: "me empeñara hasta los ojos», "él no veía más allá de su nariz», "todo le salió a pedir de boca», "vivita y coleando", "el maná no cae del cielo, ese hay que buscarlo en la tierra», "aquí todo el mundo camina», "hacer el ajiaco... que si le daban al muerto, resucitaba», "quien le ponía el cascabel al gato» o «le zumba el mango». También hay un uso de los pregones populares. Como ejemplo de esto se puede citar el que crea Reyita en su niñez cuando vendía dulces: "cómpreme dulcecitos pa' llevar a sus hijitos» o aquellos que recuerda de los vendedores ambulantes del singular barrio de Barracones.

En otra dirección, aparecen sus antepasadas, en las cuales se percibe el uso de la memoria cultural, específicamente, la africana. Los dos ejemplos que se destacan son los de "Tatica» y "Mamacita». La primera, a pesar del proceso de separación de la tierra natal, no olvida las creencias religiosas, mantiene su cosmovisión del mundo y los gustos heredados por 
generaciones; mientras que la segunda es una mujer sin prejuicios que siempre enarbola el amor por sus tradiciones.

\section{La mujer afrocubana, su memoria y raíces}

Es preciso concretar que la oralidad es el elemento fundamental de la transmisión de la memoria y las raíces. Este elemento en la obra tiene influencia tanto externa como interna. La primera está desde la génesis del texto escrito, un recuento oral que le hace Reyita a su hija Daisy. La segunda, dentro de la diégesis, debido a que el personaje protagónico cuenta las historias que a su vez fueron comunicadas de manera oral por sus antepasadas, es decir, existe una cadena de transmisión oral de las memorias. Por ejemplo, en el acápite «Mi abuelita voló», la narradora protagonista relata la historia que a su vez le contó su abuela «Tatica» sobre su vida.

En relación con la búsqueda de las raíces, a través del apartado titulado «Negros con negros», Reyita expresa cómo la discriminación y la raigambre cultural heredadas de sus antepasados negros, en especial de su abuela «Tatica», que le inculcó el amor por su tierra natal, la impulsan a querer emigrar hacia África. Por ende, se convierte en su forma de búsqueda de sus raíces.

La visión que tiene de ese continente es la del lugar de la génesis del individuo negro, el lugar idílico de la creación y el ensueño. Como resultado en esta visión, ocurre una idealización. Esta se percibe cuando Reyita no sabe en realidad ni dónde se localiza, ni las condiciones que podría poseer en ese lugar, y solo se aferra a las transmisiones orales de los antepasados africanos que vivieron en él y a las esperanzas de resolución de todas sus problemáticas. Entonces, África adquiere la condición de un locus amoenus capaz de materializar las aspiraciones sociales y espirituales de la protagonista.

Al mismo tiempo, la oralidad vuelve a ser recurrente en el acápite «Miedos y gustos», donde el personaje protagónico revela que le encanta escuchar y hacer cuentos, y, como ejemplo, narra un cuento popular tradicional haitiano sobre un matrimonio de haitianos que es burlado por otro cada domingo. Afirma que una de sus aficiones de pequeña era ir a los velorios en el campo, los que después de la medianoche se convertían en centros donde se relataban cuentos de todo tipo. Recuerda, además, que en su casa: "cuando cuatro o cinco viejos se ponían a conversar, jse decían cada cosa!: comentarios, leyendas de aparecidos, mitos... hasta sus mentiritas" (Rubiera Castillo, Reyita... 113). 


\section{La mujer afrocubana y la discriminación}

En otra cuerda, la narradora protagonista aborda la manera en que la sociedad y las concepciones arraigadas en ella habían excluido a la mujer negra drásticamente. Por lo tanto, sus objetivos centrales son describir, atacar y condenar los temas fundamentales que han marcado la situación de opresión en la mujer negra: la pobreza, el racismo y la discriminación de género. Estas son las principales batallas que debe enfrentar durante toda su vida no solo ella, sino todos los personajes femeninos negros representados. Sucesos que Reyita saca a la luz, refiriéndose desde el punto de vista colectivo e individual. Para condenar las experiencias colectivas, ella describe el contexto cubano en el cual persistían las discriminaciones hacia las mujeres afrodescendientes.

Primero, durante la Colonia, con la esclavitud, mediante la explotación, la sumisión, el servilismo o la degradación, y maltratos físicos como el abuso doméstico, laboral o sexual. Reyita advierte: "Mi mamá no era hija de Basilio, sino de uno de los amos de mi abuela. Las esclavas no se podían revirar cuando los amos deseaban aprovecharse de ellas. Eso costaba cuero y cepo" (Rubiera Castillo, Reyita... 19).

Luego, en la Neocolonia, se avista la discriminación con las desigualdades sociales que impedían el desarrollo de la mujer negra. Sobre esto abundan ejemplos que lo demuestran: el no acceso a la educación (no se podía matricular en la Escuela del Hogar o de Comercio, ni estudiar una carrera, mientras que aquellas que lo lograban y se convertían en maestras eran enviadas a trabajar a sitios intrincados en el campo); el no poder integrar agrupaciones sociales, como las sociedades "Luz de Oriente» (solo para mulatos) o "Aponte» (para mulatos y negros con nivel educacional y económico); el no acceso a la salud (la asistencia médica era pagada y se debía recurrir a remedios caseros para curar las enfermedades); y el no derecho al esparcimiento, puesto que no existían lugares dedicados a ello.

Del mismo modo, alude a los destinos que debían seguir las mujeres negras en esa época: la servidumbre, la prostitución o la muerte; así como la denuncia de actitudes discriminatorias: el aislamiento, la exclusión, el servilismo y la mutilación. Con respecto a lo último, señala cómo a las niñas negras las ponían a trabajar en la casa de los blancos donde las pelaban para evitar que se le viese el cabello. A la par, se refiere a la no solvencia económica sino a la pobreza en toda su magnitud. Por último, no deja de lado cómo los rezagos de la mentalidad racista 
permanecían en algunas personas después del triunfo de la Revolución, en el acápite "Queda mucho por hacer».

En otra dirección, el personaje protagónico va desentrañando, a lo largo de toda la obra, las problemáticas individuales de discriminación racial y de género que padecía. En relación con las de discriminación racial, se percibe, desde lo social, a través del reconocimiento, la descripción y la crítica del entorno en el que vivió.

Desde lo familiar, esta se aprecia mediante dos fenómenos. El primero, nombrado endorracismo, se define como: "el racismo desde adentro, una auto discriminación emanada del sujeto racializado, es decir, aquel que sufre y experimenta el prejuicio por su pertenencia étnicoracial... un autodesprecio instigado, en el cual el sujeto racializado por otro auto concebido como superior, acepta mirarse a sí mismo con los ojos del amo como consecuencia de la coacción racista" (Pineda, Racismo resistencia 55). El otro, denominado endoculturación familiar, se entiende como: "la transmisión de ejemplos y valores morales y laborales heredados y adquiridos en condiciones históricas de pobreza; el no aprovechamiento óptimo de las oportunidades para estudiar y trabajar, así como el verdadero papel educativo de la escuela, mucho más complejo e integral que el formalmente instructivo" (Guanche 83).

El primer fenómeno, se ejemplifica en la obra, en el acápite "Una niña negra», cuando Reyita dice: "Yo fui víctima de una terrible discriminación por parte de mi mamá" (Rubiera Castillo, Reyita... 13). Según lo que la protagonista confiesa, esto se evidencia de diferentes formas. Desde el plano verbal, a través de los elementos peyorativos, con los que Isabel caracteriza a su hija: "La negra esta, la jocicúa esta" (Rubiera Castillo, Reyita... 13) o cuando le decía: "Reyita cierra la boca que la bemba te va a llegar a la rodilla... o Reyita, tú no eres mona de nadie para que se rían de ti" (Rubiera Castillo, Reyita... 26).

Desde el plano psicológico, mediante la diferenciación entre sus hijas, la represión de las actitudes y los gustos, la incomprensión de sus aspiraciones, la negación y la vergüenza ante los demás, el enclaustramiento obligatorio y el abandono materno.

Por su parte, el segundo fenómeno se vislumbra cuando la protagonista tiene la oportunidad de estudiar y se lo comenta a los miembros de su familia, que le dicen: "Esta negrita se ha vuelto loca" (Rubiera Castillo, Reyita... 54).

La discriminación, también, se percibe en la actitud de otros familiares no consanguíneos sino políticos, a partir del racismo. Este fenómeno es conceptualizado como: 
un conjunto de ideas distorsionadas sobre la realidad, emanadas de intereses económicos concretos, compuestas de presupuestos descalificativos, degradantes y subordinantes de los individuos, por su pertenencia étnico-racial, sus formas fenotípicas, el color de piel, y que se [apoya] para su mantenimiento y reproducción en los diferentes agentes socializadores de la realidad intersubjetiva (Pineda, Racismo multiculturalidad 196).

Este se puede apreciar por medio de "aparatos socioculturales, contentivos y reproductores de la ideología racista [como]: la organización comunitaria, familiar y sexoafectiva, el lenguaje, los medios de comunicación, difusión, la educación y la religión, entre otros" (Pineda, Racismo resistencia 30).

En la obra se manifiesta a través de la crueldad que sufre en la protagonista durante la niñez en manos de «Doña Mangá». Reyita declara: "¡Pero la doña era mala! A pesar de todo lo que la ayudaba, por cualquier cosa me pegaba sin compasión!" (Rubiera Castillo, Reyita... 41).

Simultáneamente, desde la visión de otros personajes no familiares y blancos, indica que, a pesar de su matrimonio, nadie se refería a ella como "Doña», a lo que una de sus vecinas le responde: "A esa gente le dicen doña porque son blancas y tienen dinero; pero a ti, negra prieta, casada con un blanco, sí, pero pobre, ¿doña de qué? ¡Reyita!” (Rubiera Castillo, Reyita... 59).

En otra perspectiva, es vital destacar que el racismo, desde el punto de vista biologicista, trajo como consecuencia que "las prevenciones sobre el negro y lo negro [fueran] socialmente construidas a lo largo del tiempo, sustentadas en estereotipos, en tanto imágenes estandarizadas, simplificadas, de la realidad social..." (Romay Guerra, Elogio... 51). En la obra esto se aprecia con los criterios estereotipados y prejuiciosos de las vecinas de Reyita. Una creía que las mujeres negras daban a luz a niños claros que luego oscurecían y otra que pensaba que no podían tener voces finas y menos para ejercer el canto.

Igualmente, se hace referencia a las actitudes racistas de otros personajes por haberse casado con un hombre blanco y la respuesta del esposo ante ello, cuando la protagonista expresa: "Él se llevaba muy bien con el dueño del Expreso, siempre lo iba a visitar. Sin embargo, ellos nunca fueron a mi casa, ni tu papá me llevó nunca a casa de ellos; aquello me dolía" (Rubiera Castillo, Reyita... 85). 
En el acápite "¿Por qué me casé con un blanco?», Reyita intenta solucionar su problemática racial y social a través del fenómeno conocido como blanqueamiento, que "es la búsqueda de escapar de lo negro para asegurarse una mejor forma de existencia social en un contexto que valora lo blanco como sinónimo de progreso, civilización y belleza" (Viveros Vigoya, Blanqueamiento... 18). Aunque dicha búsqueda se caracteriza por tomar dos direcciones diferentes, solo una de ellas es la asumida por la protagonista, el blanqueamiento por medio del mestizaje en un proceso intergeneracional.

Esta actitud se infiere porque "el mestizaje, como una forma de blanqueamiento progresivo, se convirtió en una promesa de inclusión en la comunidad de ciudadanos no solo a través de los casamientos con personas más blancas sino por adecuación a los valores de respetabilidad y honor considerados propios de los grupos construidos como blancos" (Viveros Vigoya, Blanqueamiento... 25). No es de extrañar que los ciudadanos desearan, a través de él, ascender socialmente y se lo plantearan como una proyección individual.

En la obra, la protagonista explica los motivos de su decisión. Para los hombres negros no había posibilidades de progreso, su única posibilidad era el deporte, específicamente, el boxeo; si no era así, ellos debían volverse matones o negociantes, con un destino marcado por el presidio o la muerte, y, si eran aún jóvenes, el reformatorio. Su sentir como madre la hace aspirar a un mejor futuro para sus hijos y que estos no fuesen maltratados por ser negros.

En cuanto a la discriminación de género, ella exterioriza cómo después de casada asume actitudes de sumisión a partir de la aceptación de comportamientos patriarcales dentro de la vida cotidiana. Comparte, también, cómo sufre maltrato psicológico, infidelidad de su esposo, enclaustramiento, enajenación en el interior de la casa, no cumplimiento de sus aspiraciones, imposibilidad de tomar decisiones relacionadas con la administración del hogar y la crianza de hijos, dependencia económica a la figura masculina y un falso matrimonio.

\section{La mujer afrocubana y su identidad}

Dentro de la identidad afrocubana como temática, se pueden percibir muchos aspectos. Uno de ellos, es el uso de la medicina natural, llamada medicina tradicional. En el caso de Reyita, se presenta a través de la curandería. El empleo de remedios naturales le permite no solo prevenir o curar enfermedades, sino también solucionar problemas de diversas índoles (salud, amor o trabajo), tanto a su familia como a otros que lo necesitan, sin fines de lucro. 
El modo en el que arriba a estas capacidades lo figura con anécdotas sobre revelaciones de sueños, la gracia que poseía o su don. Así, expone: "Tú sabes que yo no creo en milagros, pero las propiedades curativas de las yerbas y raíces que utilizaba para aquellos remedios, más la fe y la buena voluntad con que los hacía, era lo que realmente curaba" (Rubiera Castillo, Reyita... 94).

De manera simultánea, explica las recetas que pone en práctica: la leche mezclada de agua de papaya para la cura de distrofia de su hijo Monín, el café en ayunas hecho con palmiche tostado y molido para la cura del asma, el agua hervida con hojas de escoba amarga para evitar la sarna o escabiosis, el zumo de hierba mora con una pizquita de bicarbonato para curar la estomatitis, el agua hervida con hojas de adelfa blanca para limpiar los impétigos, entre otros. Describe, detalladamente, su método de elaboración y de aplicación, entre ellos: la cura del empacho, del «mal de ojo», de la infertilidad y la fertilidad. Finalmente, la protagonista emplea la curandería para resolver circunstancias amorosas como la pérdida de la virginidad antes del matrimonio o de la estabilidad conyugal. Como consecuencia, la medicina tradicional demuestra todo el acervo de sabiduría popular heredado en la nación.

Otro igual de importante, es el folklor, y, dentro de este, el baile y la música. En el acápite "lyá, la panza; panza, lyá», la narradora protagonista confiesa que le gusta el baile y, aunque no había podido practicarlo, recuerda que: "Frente a la casa donde vivíamos había un grupo de muchachones que se reunía al atardecer para tocar guitarra, claves y tambores... era bien chiquita, pero me llamaba la atención... me metí en la cumbanchita... y cuando más divertida estaba bailoteando siento que me cogen por un moño y me halan, jera mi mamá! Me sacó a empujones..." (Rubiera Castillo, Reyita... 118).

Asimismo, señala su gusto por las comparsas, a través de la siguiente anécdota: "En la Maya salían muchas para las fiestas de San José. Un día con mi prima Guarina, me metí en una... Íbamos arrollando detrás de una que llevaba un cantico que decía lyá, la panza; panza, lyá. Yo iba toda desbaratada al compás de la música..." (Rubiera Castillo, Reyita... 118). A la vez, expresa su deleite por los carnavales, al ser una fiesta divertida y colectiva. Tal es así, que da un retrato pormenorizado de cómo eran los carnavales de Santiago de Cuba y las comparsas de los barrios tradicionales de El Tivolí, Los Hoyos, San Agustín y Trocha.

En otra cuerda, están los rituales. En la obra, Reyita rememora cómo en 1912 es llevada por su tía "Doña Mangá» a una sesión espiritual donde se reunían algunas mujeres médiums 
que realizaban oraciones y plegarias, y quienes culminaban dilucidando el futuro a través de lo que les mostraba un vaso lleno de agua. Luego explica que existen diferentes tipos de espiritismos y, por ende, de rituales, como se ejemplifica a continuación:

A los bayameses les gustaba el de cordón, esos creyentes, cuando se reúnen, hacen un círculo, se toman de las manos, cantan y rezan, mientras dan vueltas alrededor de las personas a quien van a quitar algún espíritu o van a consultar. Así van creando una corriente magnética, que hace caer a los fieles en trance. En Bayamo había muchos centros de esos (Rubiera Castillo, Reyita... 89).

Más tarde, revela: "Era una mediumunidad que se me desarrolló cuando comencé a trabajar la obra espiritual, en Bayamo. Yo había leído mucho sobre el espiritismo en las obras de Allan Kardec y participé en alguna que otra actividad de ese tipo" (Rubiera Castillo, Reyita... 90).

Como último aspecto, están las leyendas populares. El ejemplo que se observa en la obra está relacionado con el miedo a los jubos que aparecen en el campo, sobre lo cual Reyita refiere: “... cuentan que cuando las mujeres estaban paridas, por la noche los jubos se subían en la cama, bajeaban, con su aliento a la mujer, que se dormía profundamente; entonces le metían la cola a los niños en la boca para que creyeran que era un teto y no lloraran. Mientras tanto, ellos le mamaban la leche a la madre" (Rubiera Castillo, Reyita... 111).

\section{Sencillamente... Reyita}

Reyita, sencillamente... es la historia de vida de una mujer negra y, a su vez, representa a otras mujeres en su condición, en cuanto a raza, clase y género. Clasificada como un testimonio literario, al cumplir con las características formales de este, constituye, simultáneamente, una valiosa obra literaria afrofemenina, por el contenido que aborda a partir de diferentes temáticas, dentro de las que se destacan lo histórico, lo cultural, lo opresivo y la identidad de la mujer afrodescendiente.

El libro Reyita, sencillamente... se inserta en la serie de la literatura afrofemenina cubana. Desde la historia, reivindica el papel de la mujer negra en la historia de Cuba; desde la cultura, enarbola la conservación del componente afrocubano; desde la memoria y las raíces, transmite 
su herencia del legado africano; desde la discriminación, denuncia la opresión que han sufrido

o persiste en las mujeres afrodescendientes en la sociedad cubana; y desde la identidad, contribuye al reconocimiento de lo afro como parte inherente y esencial de la identidad nacional de Cuba.

\section{Referencias}

Álvarez Álvarez, Luis y Gaspar Barreto Argilagos. El arte de investigar el arte. Santiago de Cuba: Editorial Oriente, 2010. Impreso.

Anderson, Maya. "Testimonios de mujeres cubanas: Feminismo y afro-cubanidad en tres textos de Daisy Rubiera Castillo". Cuadernos de Literatura del Caribe e Hispanoamérica. 17. 2013: 105-116. Digital.

Capote Cruz, Zaida. La nación íntima. La Habana: Ediciones Unión, 2008. Impreso.

Da Trindades Prestes, Luciana. "Recreando la imagen literaria de la mujer afrodescendiente en las narrativas femeninas afrocubanas y afrobrasileñas contemporáneas". Diss. University of Tennessee - Knoxville, 2015. TRACE: Tennessee Research and Creative Exchange. Doctoral Dissertations. Digital.

Curiel Pichardo, Rosa Ynés Ochy. "Género, raza, sexualidad: debates contemporáneos". Universidad Nacional de Colombia. bdigital: Repositorio Institucional, 2014. Digital.

De Oviedo, José Miguel. Historia de la Literatura hispanoamericana: De los orígenes a la Emancipación. Tomo I. Madrid: Alianza Editorial, 1995. Impreso.

Egües Cruz, Arianna. "La imagen de la mujer negra en Reyita, sencillamente. Testimonio de una negra cubana nonagenaria de Daisy Rubiera Castillo". Diss. Universidad de las Villas, 2018. Impreso.

Fanon, Frantz. Piel negra, máscaras blancas. Madrid: Ediciones Akal, 2009. Impreso.

Guanche, Jesús. "África en Cuba y América: Las heridas de la esclavitud". Revista del CESLA. 5. 2003: 71-88. Digital.

Kornweibel, Karen Ruth. “Daisy Rubiera Castillo's Reyita: Mujer Negra. From Objectified Symbol to Empowered Subject". Letras Hispanas. 7. 2010: 67-79. Digital.

Martiatu Terry, Inés María y Daisy Rubiera Castillo. Afrocubanas, historia, pensamiento y prácticas culturales. La Habana: Editorial de Ciencias Sociales, 2011. Impreso.

Martiatu Terry, Inés María. "Escritoras afrocubanas en el siglo XIX: Antecedentes del feminismo negro en Cuba". Afrocubanas. Web. 2 ene. $2015<$ 
https://afrocubanas.wordpress.com/2015/01/02/escritoras-afrocubanas-en-el-sigloxix-antecedentes-del-feminismo-negro-en-cuba/>

Ramírez Chicharro, Manuel. "Doblemente sometidas: las mujeres de color en la república de Cuba (1902-1959)". Revista de Indias LXXIV. 262. 2014): 783-828. Digital.

Rivera Pérez, Aymée. "¡Oshún Okantonú!, la imagen literaria de la mujer negra en las escritoras caribeñas". Diss. Universidad de Alcalá, 2012. e-Buah: Biblioteca Digital de la Universidad de Alcalá. Tesis Doctorales. Digital.

Riverón Rojas, Ricardo. "María Dámasa Jova: la ninfa de los umbrales". Signos. 53. 2006: 5764. Digital.

Rojo, Sergio. "Discriminación racial: Discurso oficial versus realidad en Cuba postrevolucionaria”. Diss. Scholar Commons, South Florida U, 2018. Scholar Commons. Digital.

Romay Guerra, Zuleica. Elogio de la altea o las paradojas de la racialidad. La Habana: Fondo Editorial Casa de Las Américas, 2014. Impreso.

Romay Guerra, Zuleica. Cepos de la memoria: Impronta de la esclavitud en el imaginario social cubano. Matanzas: Ediciones Matanzas, 2015. Impreso.

Rubiera Castillo, Daisy. Reyita, sencillamente: Testimonio de una negra cubana nonagenaria. La Habana: Casa de las Américas, 2011. Impreso.

Rubiera Castillo, Daisy. "La mujer negra: su discurso, ayer, hoy". La Ventana. Revista Digital Casa de las Américas. Web. 21 feb. $2011<\mathrm{n}$. d.>

Salinas Carvacho, Valentina. "El pensamiento social de las mujeres negras a través de la Revista Adelante (1935-1939)". UNIVERSUM. 33. 2018: 193-213. Digital.

Showalter, Elaine. "La crítica feminista en el desierto". Textos de Teoría y Críticas Literarias: Del formalismo a los estudios poscoloniales. Comp. Nara Araujo y Teresa Delgado. Parte II. La Habana: Editorial Félix Varela, 2009. 595-638. Impreso.

Stolcke, Verena. "La mujer es puro cuento: la cultura del género". Estudos Feministas, Florianópolis. 12.2. 2004: 77-105. Digital.

Tobón, Natalia. "La realidad y la ficción del testimonio". Nomadasyrebeldes. Web. oct. 2013. < https://nomadasyrebeldes.files.wordpress.com/2013/10/texto-testimonial.pdf >

Viveros Vigoya, Mara. "La sexualización de la raza y la racialización de la sexualidad en el contexto latinoamericano actual". Memorias del 1er. Encuentro Latinoamericano y del 
Caribe: La sexualidad frente a la sociedad. Comp. Gloria Careaga. México: Sigma Servicios Editoriales, 2008. 168-198. Digital.

Viveros Vigoya, Mara. "Blanqueamiento social, nación y moralidad en América Latina". Enlaçando sexualidades: uma tessitura interdisciplinar no reino das sexualidades e das relações de gênero. Comp. Suely Messeder, María García Castro y Laura Moutinho. Salvador: EDUFBA, 2016. 17-39. Digital.

Wade, Peter. Raza y etnicidad en Latinoamérica. Quito: Ediciones Abya-Yala, 2000. Digital. 